Received: 2 February 2018

Accepted: 3 August 2018

Published online: 24 August 2018

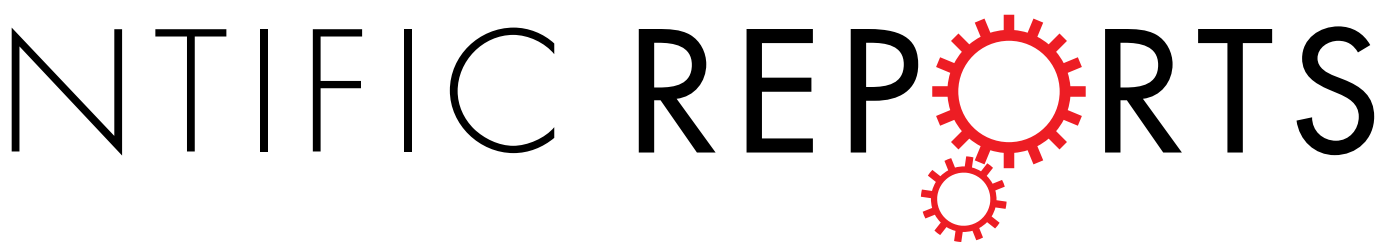

\title{
OPEN The UV/Visible Radiation Boundary Region (385-405 nm) Damages Skin Cells and Induces "dark" Cyclobutane Pyrimidine Dimers in
Human Skin in vivo
}

\author{
Karl P. Lawrence $\mathbb{D}^{1}$, Thierry Douki ${ }^{2}{ }^{2}$, Robert P. E. Sarkany ${ }^{1}$, Stephanie Acker ${ }^{3}$, \\ Bernd Herzog ${ }^{3}$ \& Antony R. Young ${ }^{1}{ }^{1}$
}

The adverse effects of terrestrial solar ultraviolet radiation (UVR) $(-295-400 \mathrm{~nm})$ on the skin are well documented, especially in the UVB region $(-295-320 \mathrm{~nm})$. The effects of very long-wave UVA ( $>380 \mathrm{~nm})$ and visible radiation $(\geq 400 \mathrm{~nm}$ ) are much less known. Sunscreens have been beneficial in inhibiting a wide range of photodamage, however most formulations provide very little protection in the long wave UVA region (380-400 $\mathrm{nm}$ ) and almost none from shortwave visible wavelengths (400-420 nm). We demonstrate photodamage in this region for a number of different endpoints including cell viability, DNA damage (delayed cyclobutane pyrimidine dimers), differential gene expression (for genes associated with inflammation, oxidative stress and photoageing) and induction of oxidizing species in vitro in $\mathrm{HaCaT}$ keratinocytes and in vivo in human volunteers. This work has implications for phototherapy and photoprotection.

Terrestrial solar radiation has long been known to induce damage to the skin. The effects of ultraviolet radiation (UVR) (particularly UVB (280-320 nm) wavelengths) are well established, however the effects of longer wavelength radiation (especially longwave UVA1 $(\geq 380 \mathrm{~nm})$ and visible light $(\geq 400 \mathrm{~nm}))$ are less studied. Visible radiation can penetrate much deeper into the skin than UVB, potentially coming into contact with a greater number of chromophores. It is also a spectral region that causes significant damage in people with photodermatoses such as erythropoietic protoporphyria (EPP) and solar urticaria. EPP is caused by an accumulation of protoporphyrin IX $\left(\lambda_{\max }=408 \mathrm{~nm}\right)$. UVA1 $(340-400 \mathrm{~nm})$ phototherapy is also used to treat a number of skin conditions such as atopic dermatitis, scleroderma and mycosis fungoides. Treatment for these conditions requires exposure to extremely high cumulative doses of UVA1, with some treatment regimes leading to total doses in excess of $2000 \mathrm{~J} /$ $\mathrm{cm}^{2}$ and individual treatment doses of up to $120 \mathrm{~J} / \mathrm{cm}^{21,2}$. Despite this, photobiology and photoprotection in this region of the solar spectrum are not well studied and poorly understood.

Much of the damage that occurs by the UVA region is attributed to the induction of oxidative stress. This has also been confirmed into the visible region; with one study demonstrating a dose dependent increase in reactive oxygen species (ROS) concentration with doses of visible light equivalent to 20-90 mins of summer sun in Texas, USA $^{3}$. Another in vivo study showed that ROS generated by visible light and infrared (IR) radiation account for $\sim 50 \%$ of total ROS caused by solar $\mathrm{UVR}^{4}$. Production of ROS is significant as they can damage many cellular molecules such as proteins, DNA and lipids ${ }^{5,6}$.

Action spectra have been determined for different types of DNA damage across the UVR and visible regions. UVA1 is much more potent than visible light, but the data are limited with conflicting results ${ }^{7-9}$. The cyclobutane pyrimidine dimer (CPD) is an important lesion in the pathogenesis of skin cancer ${ }^{10}$. Kielbassa et al. reported an in vitro action spectrum for CPD that shows their generation up to $400 \mathrm{~nm}^{9}$. Another study by Liebel showed

${ }^{1}$ St. John's Institute of Dermatology, King's College London, Guy's Hospital, London, SE1 9RT, UK. 'University Grenoble Alpes, CEA, CNRS, INAC-SyMMES/CIBEST, 38000, Grenoble, France. ${ }^{3}$ BASF Grenzach GmbH, GrenzachWhylen, 79639, Germany. Correspondence and requests for materials should be addressed to K.P.L. (email: karl. lawrence@kcl.ac.uk)or A.R.Y. (email: antony.young@kcl.ac.uk) 
a.

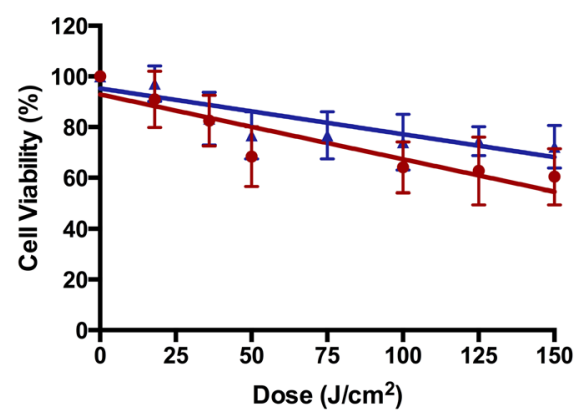

b.

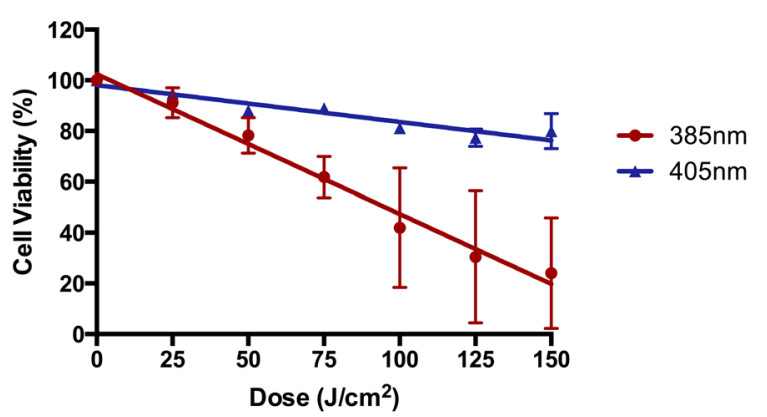

Figure 1. Wavelengths at the UV/visible border $(385-405 \mathrm{~nm})$ significantly reduced cell viability in vitro in a dose dependent manner. The Neutral Red assay (a) showed a significant dose dependent decrease in cell viability for both wavelengths ( $385 \mathrm{~nm}-\mathrm{p}<0.0001 ; 405 \mathrm{~nm} \mathrm{p}<0.0001 ; \mathrm{n}=3$ linear regression analysis) with no significant difference between the wavelengths ( $\mathrm{p}<0.1559 ; \mathrm{n}=3$, linear regression analysis). For Alamar Blue (b) there was a significant dose dependent decrease in cell viability for both wavelengths $(385 \mathrm{~nm}-\mathrm{p}<0.0001$; $405 \mathrm{~nm}-\mathrm{p}<0.0001 ; \mathrm{n}=3$ linear regression analysis). There was a significant difference between wavelengths $(\mathrm{p}<0.0001 ; \mathrm{n}=3$, linear regression analysis). Data points represent the mean $\pm \operatorname{SD}(\mathrm{n}=3)$.

that CPDs, specifically thymine dimers $(\mathrm{T}<>\mathrm{T})$, were not induced by broad-spectrum visible light ${ }^{3}$. This has been further complicated by the recent demonstration of delayed or 'dark' CPDs, in melanocytes in vitro and pigmented mice by broad-spectrum UVA irradiation, which are formed over 4 hrs post-irradiation, and thought to be due to the chemoexcitation of chromophores such as melanin ${ }^{11}$ however this has also been reported in cells lacking melanin ${ }^{12}$. Melanin has also been shown to play a role in visible light induced DNA damage, resulting in DNA strand breaks, and oxidative pyrimidine modification in melanocytes in vitro but not in the melanin deficient (albino) equivalent ${ }^{13}$. The phototoxic potential of melanin and its consequences have also previously been described $^{11,13-17}$.

Both ROS and DNA damage induction have been linked to the expression of a range of genes. Differential expression of mRNA has been demonstrated in human epidermal equivalents exposed to different doses of visible light, with a significant increase in IL-1 $\alpha$, IL-6, GM-CSF and IL-8 mRNA expression ${ }^{3}$. Matrix metalloproteinases (MMP) are thought to be important in skin photoageing ${ }^{18}$. MMP-1 and MMP-9 protein production also increased significantly in vivo in response to visible and infrared radiation combined ${ }^{19}$. However, another study found no significant change in MMP-1 protein expression in vivo after exposure to blue light ${ }^{20}$. UVR exposure of the skin has also been shown to regulate hormones and the neuroendocrine system, for example in the photoproduction of vitamin D and UV induced stimulation of $\beta$-endorphin ${ }^{21}$.

The aim of this study was to investigate the effect of exposure to wavelengths at the UV/visible border region $(385-405 \mathrm{~nm})$ using in vitro and in vivo human models. We investigated a range of endpoints including cell viability, oxidizing species, DNA damage (including delayed CPD) and differential gene expression. This work has consequences for UVA1 phototherapy and photoprotection, as this region is largely neglected by current sunscreen formulations.

\section{Results}

Cell Viability Reduction In Vitro. Cell viability was measured 24 hrs post exposure using the Neutral Red and Alamar Blue methods (Fig. 1). There was a significant dose dependent reduction in cell viability with 385 and $405 \mathrm{~nm}$ spectra with both assays. In the case of the Neutral Red assay, there was no significant difference between the wavelengths, however $385 \mathrm{~nm}$ was significantly more lethal with the Alamar Blue assay.

Induction of Oxidizing Species In Vitro. For both $385 \mathrm{~nm}$ and $405 \mathrm{~nm}$ there was a significant dose dependent increase in oxidizing species formation (Fig. 2). The slopes of both sources were compared and it was shown that significantly more oxidizing species were produced with $385 \mathrm{~nm}$ exposure than $405 \mathrm{~nm}$. The $405 \mathrm{~nm}$ source demonstrated good linearity but there was a trend towards a plateau.

CPD Induction. CPD Induction In vitro. HaCaT keratinocytes were exposed to acute increasing doses $\left(0-150 \mathrm{~J} / \mathrm{cm}^{2}\right)$ of each source, and CPD lesions were assessed by IHC-IF immediately post exposure $(0 \mathrm{hrs})$. The $385 \mathrm{~nm}$ source produced a significant increase in CPD at $150 \mathrm{~J} / \mathrm{cm}^{2}$. There was no significant increase detected at any of the doses with the $405 \mathrm{~nm}$ source. The results are displayed in Fig. 3.

CPD Induction In vivo Human Skin. There was an increase in CPD lesions over 2 hrs post exposure with the $385 \mathrm{~nm}$ source that was maintained over a 24 -hr period with no evidence of repair (Fig. 4). There was a slight increase in CPD with the $405 \mathrm{~nm}$ source but this was only detected in two samples. The high value for the $0 \mathrm{hr}$ time point with the $385 \mathrm{~nm}$ source is a probable single outlier. 


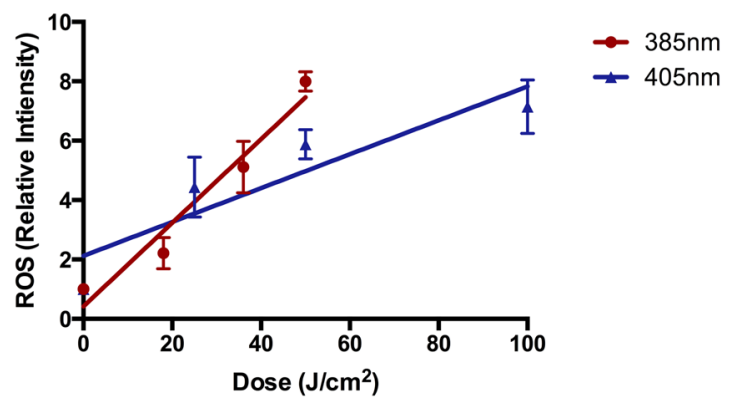

Figure 2. $385 \mathrm{~nm}$ and $405 \mathrm{~nm}$ significantly induced the formation of ROS in a dose dependent manner in vitro when measured with the $\mathrm{H}_{2}$ DCFDA assay. For both sources, there was a significant dose dependent increase in ROS production ( $385 \mathrm{~nm}: \mathrm{p}<0.0001,405 \mathrm{~nm}: \mathrm{p}=0.0001 ; \mathrm{n}=3$; linear regression analysis) with a significant difference between the slopes of both wavelengths $\mathrm{p}=0.0001 ; \mathrm{n}=3$; linear regression analysis). Each point represents the mean $\pm \mathrm{SD}(\mathrm{n}=3)$.
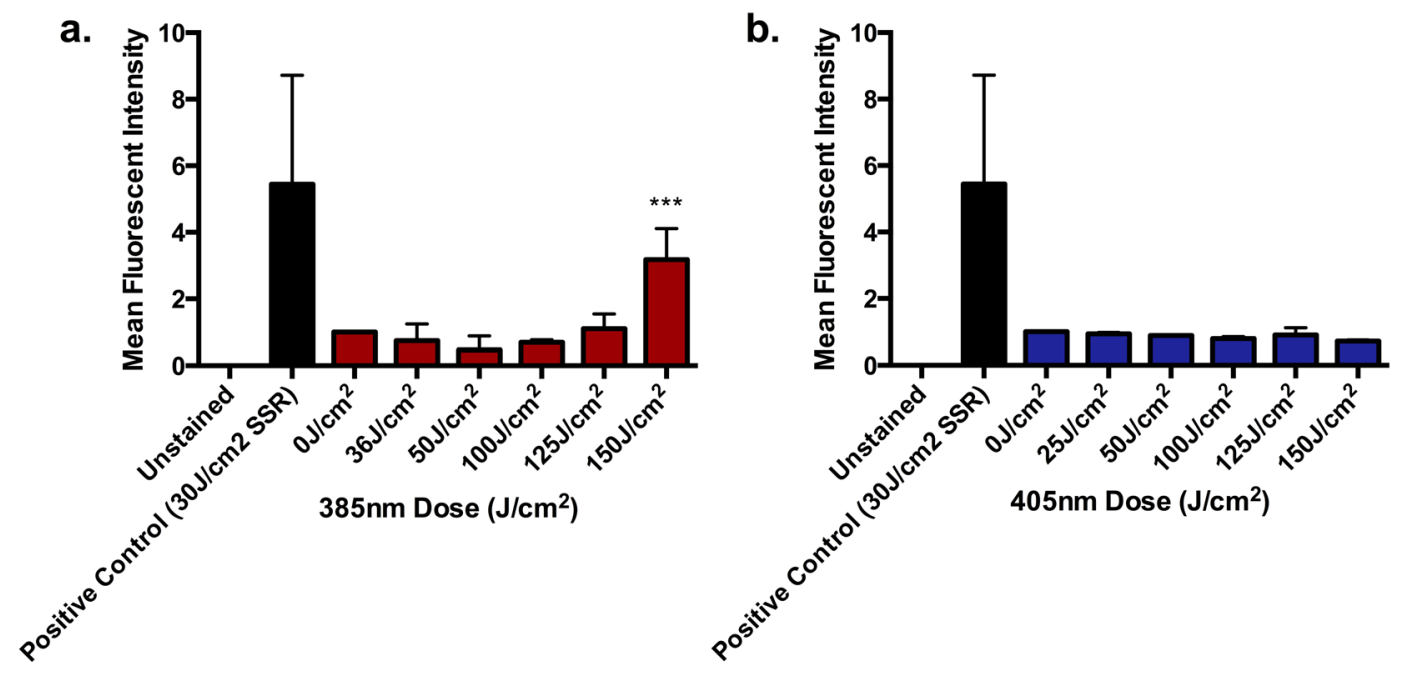

Figure 3. The ability of wavelengths at the UV/visible border $(385-405 \mathrm{~nm})$ to induce CPD in vitro when measured by IHC-IF. HaCaT keratinocytes were untreated, or exposed to $0-150 \mathrm{~J} / \mathrm{cm}^{2}$ of (a) $385 \mathrm{~nm}$ or (b) $405 \mathrm{~nm}$ radiation. CPD were measured immediately post exposure using IHC-IF. Columns represent mean $\pm S D(n=3)$. There was a significant increase in CPD at the highest dose of $385 \mathrm{~nm}$ radiation $(\mathrm{p}<0.0001$; $\mathrm{n}=3$, one-way ANOVA with Dunnett's multiple comparisons test). There was no significant increase in CPD formation at any dose with the $405 \mathrm{~nm}$ source.

Gene expression. The effect of the UV/visible border region on differential gene expression was assessed in vitro and in vivo human skin with responses compared.

Gene Expression in vitro. Doses were selected to maintain a cell viability of $\geq 75 \%$. $12 \mathrm{hrs}$ post exposure, total RNA was extracted from the cells as described in the Materials and Methods. The results are displayed in Fig. 5. The dose response relationship of all the genes was assessed using linear regression analysis and the difference in the slopes between $385 \mathrm{~nm}$ and $405 \mathrm{~nm}$ compared. The results of the statistical comparisons are displayed in Table 1.

In general there was a significant dose dependent upregulation in gene expression for the majority of genes tested at $385 \mathrm{~nm}$ and $405 \mathrm{~nm}$. The $385 \mathrm{~nm}$ source was more efficient at inducing an upregulation of gene expression for all tested genes.

Gene expression in vivo. In vivo gene expression was measured by qPCR in skin type I-III human volunteers irradiated with an acute dose of $150 \mathrm{~J} / \mathrm{cm}^{2}$ of $385 \mathrm{~nm}$ and $405 \mathrm{~nm}$, with biopsies taken at 6 and $24 \mathrm{hrs}$. The details of the volunteers are listed in Materials and Methods. Many genes across all endpoints demonstrated an upregulation in response to both wavelengths. The results for individual genes are displayed in Supplementary Figure S1.

The pooled data are displayed in Fig. 6 and results of the statistical analyses described in Table 2. Genes associated with inflammation and photoageing were significantly upregulated in the treated groups, compared to unirradiated control at both $385 \mathrm{~nm}$ and $405 \mathrm{~nm}$. There was no significant increase in genes associated with 

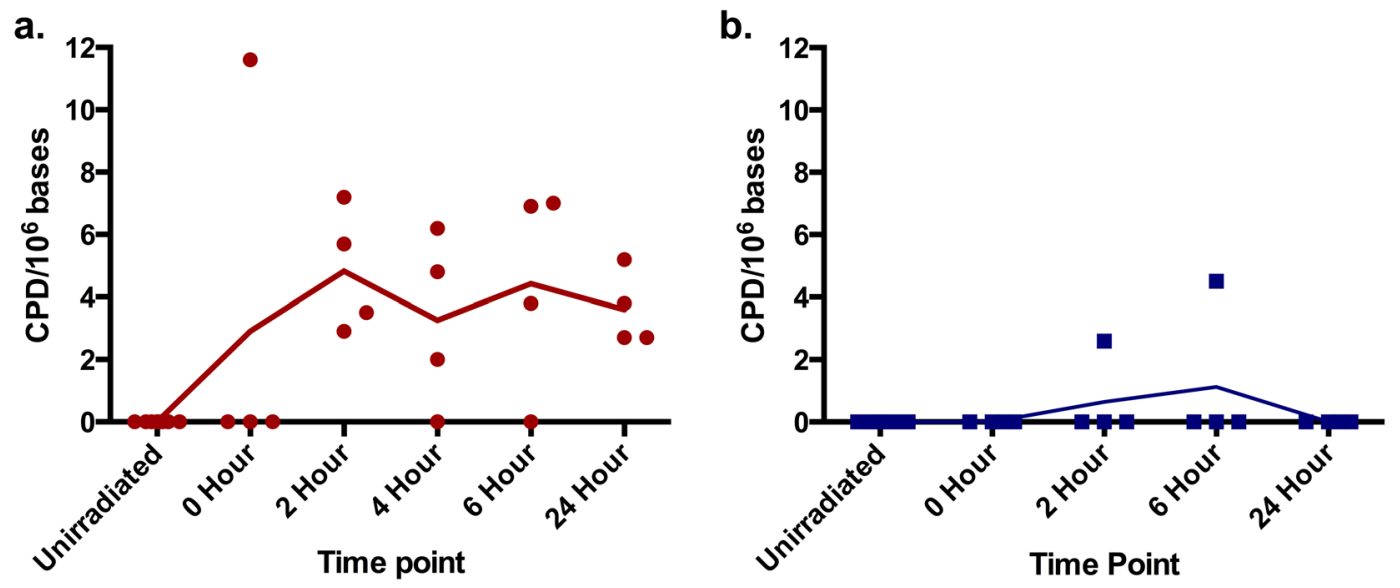

Figure 4. The ability of wavelengths at the UV/visible border (385-405 nm) to induce CPD over time in vivo assessed by HPLC-MS/MS. Human volunteers were unexposed, or exposed to $0-150 \mathrm{~J} / \mathrm{cm}^{2}$ of (a) $385 \mathrm{~nm}$ or (b) $405 \mathrm{~nm}$ radiation. Biopsies were taken 0-24 hrs post exposure. DNA was extracted and CPDs were assessed by HPLC MS/MS. Each point represents mean ( $\mathrm{n}=4$ per time point, from 8 volunteers). The high 0 Hour value with the $385 \mathrm{~nm}$ source is a probable outlier.

oxidative stress with either source. In general, there was no significant difference in the upregulation of genes between sources. The one exception was the photoageing genes at $24 \mathrm{hrs}$, where there was no significant increase at $24 \mathrm{hrs}$ with the $405 \mathrm{~nm}$ source. There was however a significant increase at $6 \mathrm{hrs}$.

\section{Discussion}

Terrestrial solar radiation comprises UV, visible and IR radiation wavebands. However, most photobiological studies on human skin have focussed on the UVR spectrum, with many studies concentrating on the shortwave UVB wavelengths. Scientists are beginning to realise the importance of the UVA1, visible and IR parts of the solar spectrum with a recent increase in published studies on these wavebands. One spectral region that is still largely neglected is the UV/visible border (375-415 nm). This region is of particular interest because it is currently poorly protected by many sunscreens and it is used at high doses for UVA1 phototherapy (e.g. lamps with 99.7\% UVA1, $\lambda_{\text {Max }}=383 \mathrm{~nm}$ ). This region is also not currently represented in standard sunscreen testing procedures for both sun protection factor (SPF) and UVA protection factor (UVA-PF), which both use a defined broad-spectrum source that has sharply decreasing output above $\sim 365 \mathrm{~nm}$. The SPF test uses solar simulated radiation (SSR) that is not representative of natural sunlight at wavelengths $>365 \mathrm{~nm}$ and potentially overestimates the SPF by sunscreens by neglecting this part of the solar spectrum ${ }^{22}$. Exposure to this region is also responsible for the distressing cutaneous symptoms of some photosensitivity disorders such as EPP and solar urticaria, indicating the potential biological activity of this waveband in pathological states. UVA1 and visible light exposure have also been linked to the production of nitric oxide (NO) (linked to blood pressure reduction) ${ }^{23-25}$ and pigmenta$\operatorname{tion}^{26}$ (linked to signalling through skin Opsin $3^{27}$ ), however these studies focussed on broader and/or different wavebands of radiation from those used in the current study. The sources used in this study cover this neglected interest. Narrowband sources have advantages over a more broad-spectrum source because the relative contribution of each part of the spectrum can be determined. This allows for more robust conclusions pertinent to photoprotection and phototherapy.

The results obtained from Neutral Red and Alamar Blue cell viability assays informed the doses used for later studies. Both assays resulted in a significant dose dependent reduction in cell viability at both wavebands. Neutral Red showed no significant difference between the wavebands, and in both cases, doses as low as $50 \mathrm{~J} / \mathrm{cm}^{2}$ induced statistically significant death (however doses of over $100 \mathrm{~J} / \mathrm{cm}^{2}$ were needed to reduce viability below $75 \%)$. However, the $385 \mathrm{~nm}$ source was significantly more potent than the $405 \mathrm{~nm}$ source with the Alamar Blue assay. This may be due to how these assays measure cell viability. Briefly, Neutral Red measures cell membrane integrity whereas Alamar Blue determines reduction potential. Both spectral regions induced oxidative stress, with $385 \mathrm{~nm}>405 \mathrm{~nm}$. This may lead to Alamar blue measuring a reduced cytoplasmic reduction potential rather than cell viability per se.

Generation of ROS by UVA and visible wavelengths is well-established in vitro ${ }^{3,28,29}$. The exact cellular photosensitizers remain unknown but $\beta$-carotene ${ }^{30}$, porphyrins ${ }^{31,32}$, flavins ${ }^{29,33,34}$ and melanins ${ }^{11,13-15}$ have all been proposed. This damage is particularly important as oxidative stress has been associated with DNA damage, leading to mutations, and protein oxidation, reducing the efficacy of DNA repair enzymes $5,7,35,36$.

The UVR wavelength dependence for most abundant and biologically relevant type of DNA damage, CPD, has been studied, with the non-solar UVC region causing the maximal effect in vitro, reflecting the absorption spectrum of $\mathrm{DNA}^{37}$. In practice, most $\mathrm{CPD}$ in the skin are caused by solar $\mathrm{UVB}^{38}$, but there are numerous reports of UVA-induced CPD, although with a lower efficiency, and many of these studies focus on the shorter end of the UVA region $(<370 \mathrm{~nm})^{9,39-43}$.

There are conflicting reports about CPD production by the UV/visible boundary region ${ }^{3,7}$. No CPD were detected in vitro immediately post exposure with the highest $405 \mathrm{~nm}$ dose $\left(150 \mathrm{~J} / \mathrm{cm}^{2}\right)$ but the same dose of 


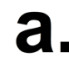

IL-1a

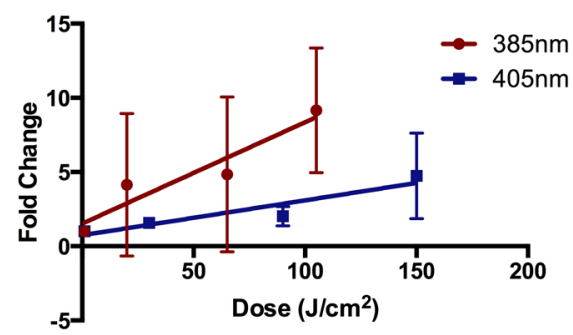

IL-6

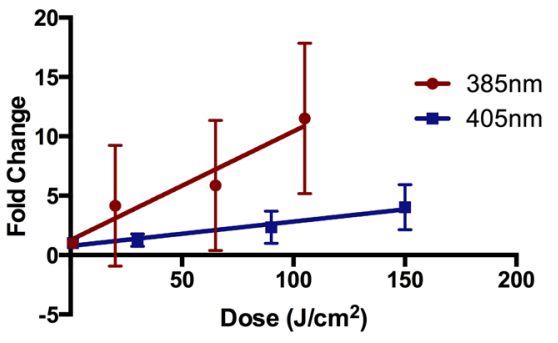

b.

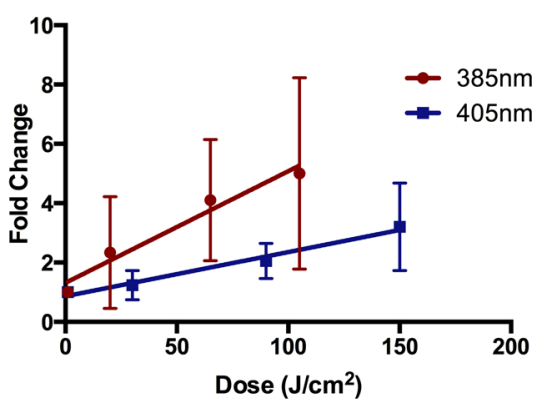

c.

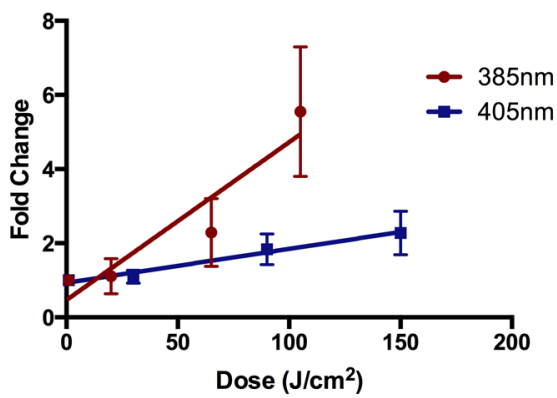

IL-8

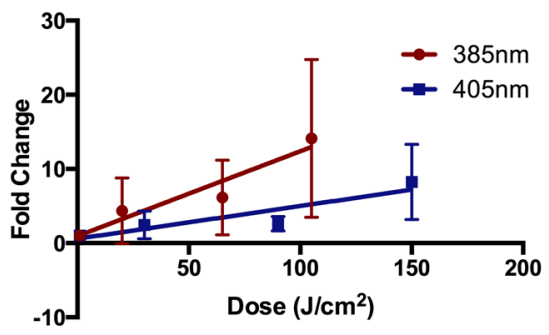

MMP-9

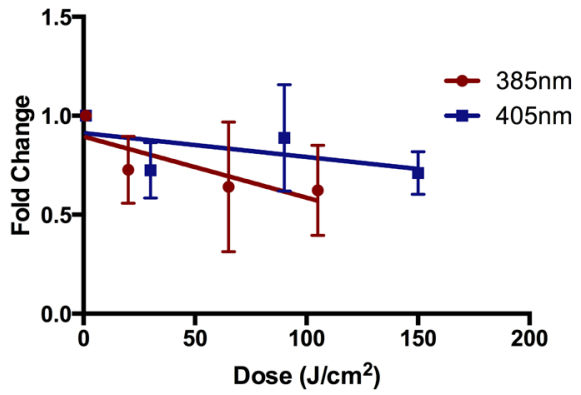

PON-2

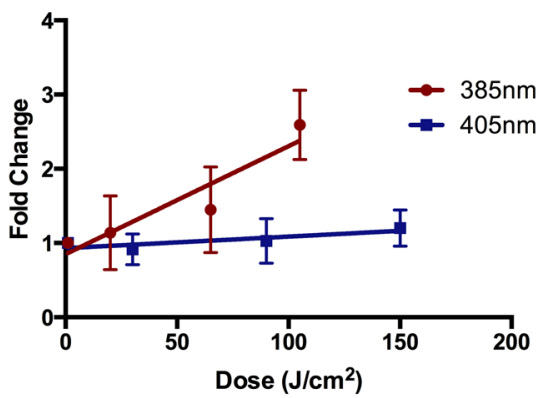

Figure 5. $385 \mathrm{~nm}$ and $405 \mathrm{~nm}$ induced gene expression changes in vitro. Genes were categorised based on (a) inflammation (b) photoageing or (c) oxidative stress. HaCaT keratinocytes were exposed to $0-105 \mathrm{~J} / \mathrm{cm}^{2}$ of $385 \mathrm{~nm}$ or $405 \mathrm{~nm}$ radiation. Gene expression changes were measured $12 \mathrm{hrs}$ post exposure by qPCR. Columns represent the mean $\pm S D(n=4)$. There was a significant upregulation in many of the genes. The slopes of both $385 \mathrm{~nm}$ and $405 \mathrm{~nm}$ response were compared and, in general, there was significant fold change in gene expression with all genes with the exception of PON-2, HMOX-1 and IL-6. Results of statistical analysis are displayed in Table 1.

$385 \mathrm{~nm}$ resulted in a low but significant increase, with none detected at lower doses. This supports reports of a slight increase in CPD with UVA1 in AS52 Chinese hamster cells but virtually none with visible radiation (doses up to $\left.150 \mathrm{~kJ} / \mathrm{m}^{2}\right)^{9}$. The $385 \mathrm{~nm}$ in vivo data provide the first evidence for 'dark' CPD in human skin in vivo as they increased over $2 \mathrm{hrs}$ and persisted for $24 \mathrm{hrs}$. These results suggest the formation CPD by a route other than direct 


\begin{tabular}{|l|c|c|c|}
\hline Gene & $\mathbf{3 8 5} \mathbf{n m}$ p value & $\mathbf{4 0 5} \mathbf{n m}$ p value & $\mathbf{3 8 5} \mathbf{n m}$ vs. $\mathbf{4 0 5} \mathbf{n m}$ \\
\hline IL-1a & 0.0142 & $\mathbf{0 . 0 0 2 7}$ & 0.0596 \\
\hline IL-6 & $\mathbf{0 . 0 0 6 6}$ & $\mathbf{0 . 0 0 1 0}$ & $\mathbf{0 . 0 0 9 7}$ \\
\hline IL-8 & $\mathbf{0 . 0 0 8 2}$ & $\mathbf{0 . 0 0 3 0}$ & 0.0580 \\
\hline MMP-1 & $\mathbf{0 . 0 0 8 7}$ & $\mathbf{0 . 0 0 0 6}$ & 0.0576 \\
\hline MMP-9 & $\mathbf{0 . 0 3 9 9}$ & 0.1510 & 0.2298 \\
\hline HMOX-1 & $<\mathbf{0 . 0 0 0 1}$ & $<\mathbf{0 . 0 0 0 1}$ & $<\mathbf{0 . 0 0 0 1}$ \\
\hline PON-2 & $\mathbf{0 . 0 0 0 2}$ & 0.1122 & $<\mathbf{0 . 0 0 0 1}$ \\
\hline
\end{tabular}

Table 1. Results of the statistical analysis of differential gene expression in vitro. $385 \mathrm{~nm}$ was more responsive in all comparisons. Displayed are the linear regression analyses p values (slope) for each gene and wavelength, and a comparison of the slopes between wavelengths. Values in bold represent statistically significant results.

\begin{tabular}{|l|l|l|l|c|l|}
\hline \multicolumn{2}{|c|}{} & Inflammation & Photoageing & $\begin{array}{l}\text { Oxidative } \\
\text { Stress }\end{array}$ \\
\hline \multirow{3}{*}{ ANOVA result } & \multirow{3}{*}{ Relationship } & Interaction & 0.6129 & $\mathbf{0 . 0 0 0 1}$ & 0.9950 \\
\cline { 3 - 6 } & & Time & 0.2629 & $<\mathbf{0 . 0 0 0 1}$ & $\mathbf{0 . 0 0 2 1}$ \\
\cline { 3 - 6 } & Wavelength & 0.9626 & $\mathbf{0 . 0 0 8 7}$ & 0.9777 \\
\hline
\end{tabular}

Table 2. The statistical analysis of pooled gene expression changes. A two-way ANOVA with Sidak's multiple comparisons test was performed on the pooled in vivo gene expression data assessing the relationship for time point and wavelengths of light. Values in bold represent statistically significant results.

a.

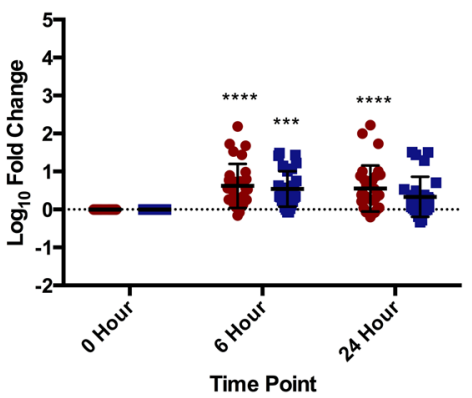

b.

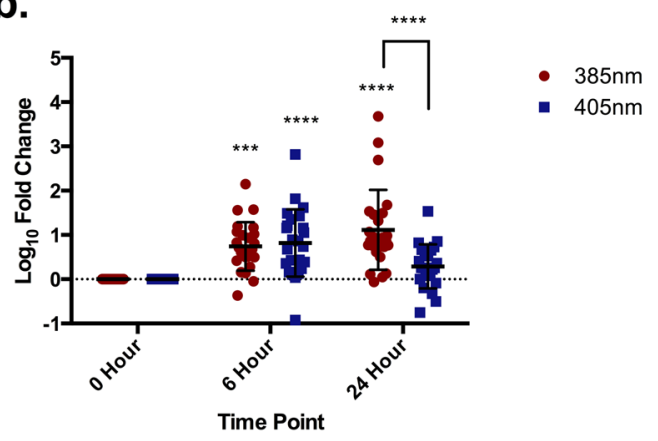

C.

- $385 \mathrm{~nm}$

- $405 \mathrm{~nm}$

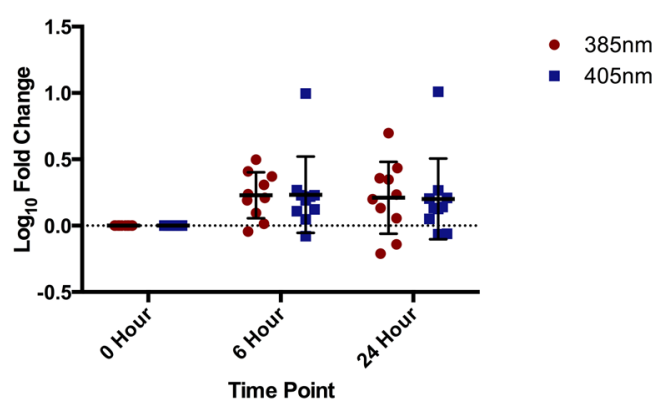

Figure 6. Pooled $385 \mathrm{~nm}$ and $405 \mathrm{~nm}$ induced gene expression changes in vivo at 6 and 24 hrs post exposure. Genes were pooled based on endpoint: (a) inflammation, (b) photoageing and (c) oxidative stress. Volunteers were exposed to $150 \mathrm{~J} / \mathrm{cm}^{2}$ of 385 or $405 \mathrm{~nm}$ radiation. Data are displayed as mean $\pm S D$ with the responses of five volunteers pooled based on endpoint. Differences were analysed using two-way ANOVA with Sidak's multiple comparisons test with results displayed in Table 2.

absorption of radiation by DNA as no CPD were detected immediately post irradiation (ignoring the single outlier $)^{11,12}$. Melanin has also been shown to play a role in DNA damage caused by visible light, with strand breaks, FPG and EndoIII sensitive lesions detected ${ }^{13}$. Despite melanin acting as an excellent photoprotectant ${ }^{44}$ (particularly in darker skin types), there is evidence for its photosensitizing potential through the photogeneration of 
$\operatorname{ROS}^{45-47}$. Other sensitizers may also act in a similar way ${ }^{48}$ and multi-chromophore excitation may be involved. Melanin photosensitization could explain the results of Tewari et al., who reported increased UVA1-induced CPD with epidermal depth in human skin in vivo, (in direct contrast with the results observed with UVB (300 nm)) given that melanin concentration also increases with epidermal depth ${ }^{43,44}$. The quantitative CPD assay required the destruction of the tissue so we lack information on the localization of the lesions. It could be expected that other endogenous skin chromophores might cause CPDs through similar mechanisms ${ }^{12}$. Very unusually, there was no evidence of repair even at $24 \mathrm{hrs}$ post exposure, at which time there is usually good repair with CPD induced by SSR ${ }^{49}$. There are a number of possible explanations for this. Firstly the levels of CPD are relatively low, so perhaps there is a threshold that must be reached before the DNA damage repair response is triggered. Another possible explanation is that there is so much oxidative stress induced that it damages the DNA repair enzymes and leads to a loss of function (as previously demonstrated by broadband UVA irradiation ${ }^{5,50}$ ) or there is a longer-term production of CPD (through photo/chemo-excitation mechanisms ${ }^{11,12}$ ) that masks any repair. This lack of repair suggests that there will be an accumulation of CPD with repeated lower level exposure, as has been demonstrated with repeated sub-erythemal exposure with SSR ${ }^{51}$. Here it should be noted that the exposures given in the current manuscript were sub-erythemal (manuscript in preparation). The generation of 'dark' CPD by longer wavelength UV/light, may have clinical significance for skin cancer even if the number of CPD is relatively low compared to UVB. The spectral dependence of "dark" CPD is unknown and its elucidation may help with the identification of chromophores. Skin cancers result from mutations in keratinocyte stem cells and melanocytes, which reside in the basal epidermis at the epidermo-dermal junction. The deeper penetration of these longer wavelengths means that CPD created by longer wavelength UVA and visible light are more likely to occur in the cells responsible for skin cancer induction. Thus, the carcinogenic potential of these longer wavelengths may be greater.

UVR has been widely implicated in differential gene and protein expression, with different spectral regions responsible for different effects. The endpoints selected were based on our previous human in vivo work ${ }^{52}$. These comprised three main categories: inflammation/immunoregulation, matrix metalloproteinases (as a marker of photoageing) and oxidative stress. Changes in gene expression were initially measured in vitro and then in vivo. The in vitro results demonstrate significant increases in many of the genes for all categories for both $385 \mathrm{~nm}$ and $405 \mathrm{~nm}$. The exceptions were MMP-9 and PON-2. MMP-9 expression was slightly down regulated with $385 \mathrm{~nm}$ with no effect at $405 \mathrm{~nm}$. For PON-2 there was a significant upregulation with $385 \mathrm{~nm}$ that was not seen with $405 \mathrm{~nm}$. The difference in PON2 expression can be explained by the greater oxidative potency of $385 \mathrm{~nm}$ compared to $405 \mathrm{~nm}$, however the difference with MMP-9 needs to be investigated further. Neither PON-2 nor MMP-9 showed any effect at $405 \mathrm{~nm}$. These differences may reflect different chromophores for different genes. It is evident that both wavelengths significantly induce markers of inflammation and photoageing at a cellular level, with the upregulation of HMOX-1 corroborating with the data from the oxidizing species assay.

The in vivo human data demonstrate a much greater increase and range of responses in gene expression changes compared to the in vitro data, however the general trends are comparable and similar to UVR responses reported by previously ${ }^{52,53}$. Combining the in vitro DNA damage and photoageing results is particularly interesting as there is some debate about the trigger for the expression of MMPs. Some studies suggest it is the formation of CPDs whilst others link this to oxidative stress, but this may vary with different $\mathrm{MMP}^{19,53-55}$. The doses used in the gene expression studies induced no/few measurable CPDs with $405 \mathrm{~nm}$ but significantly increased MMP mRNA; suggesting independence from CPD, but related to oxidative damage. The different time courses of MMP expression observed in vivo with UVB/broadband UVA or the visible border region may be due to MMP expressed via one of these two possible mechanisms $s^{3,53,54}$. There was no significant change in genes linked to oxidative stress (despite the increase in ROS detected in vitro), matching the previous studies by Tewari et al. ${ }^{52}$, but the in vitro gene expression experiments showed more significant changes. This suggests better anti-oxidant defence mechanisms in vivo.

Gene expression responses in vitro and in vivo were compared to justify the use of the in vitro model (Supplementary Figure S2), as there are concerns with the use of HaCaT keratinocytes with a p53 mutation ${ }^{56}$ (a protein important in cell cycle and repair). In general, there was no significant difference in the magnitude of the responses of the genes after irradiation with either $385 \mathrm{~nm}$ or $405 \mathrm{~nm}$ between in vitro and in vivo experiments. The only exception was with MMP-1 induction with both $385 \mathrm{~nm}$ and $405 \mathrm{~nm}$, where MMP-1 was significantly more upregulated in vivo compared to in vitro, although the trends were same. These results validate the use of the in vitro $\mathrm{HaCaT}$ keratinocyte model for gene expression studies, as overall there is an excellent correlation between the in vitro model and the in vivo response. A significant benefit of this work is the same sources and experimental conditions were shared between in vitro and in vivo studies - this is not the case in many comparisons.

The highest doses used in this study are slightly higher than would be possible to receive in a full day's exposure to the sun in a tropical environment, although many of the effects were observed at lower doses that would be possible ${ }^{57}$. The doses are particularly relevant to UVA1 phototherapy that uses high dose $\left(>60 \mathrm{~J} / \mathrm{cm}^{2}\right)$ exposure to a source peaking in the UVA1 waveband at $383 \mathrm{~nm}$ several times a week (3-5 sessions) for many weeks (typically 10 weeks). This can lead to extremely high cumulative doses and there is little known about the long-term safety of this treatment ${ }^{58}$. This study only used a single exposure and found significant damage, so the effect of repeated exposures needs to be investigated.

In conclusion, the data demonstrate that the UV/visible boundary wavelengths cause significant biologically relevant damage in vitro and in vivo, including dark CPD formation. This damage is most likely caused by oxidative stress generated by chromophores in the skin such as protoporphyrin IX, $\beta$-carotene and melanins that absorb strongly in this region, although this would require further investigation. These effects have implications for the possible need to extend photoprotection in the normal population to longer wavelengths, and for UVA1 phototherapy. They raise the need for photoprotection in this region and the inclusion of wavelengths longer than $380 \mathrm{~nm}$ in sunscreen testing protocols. 


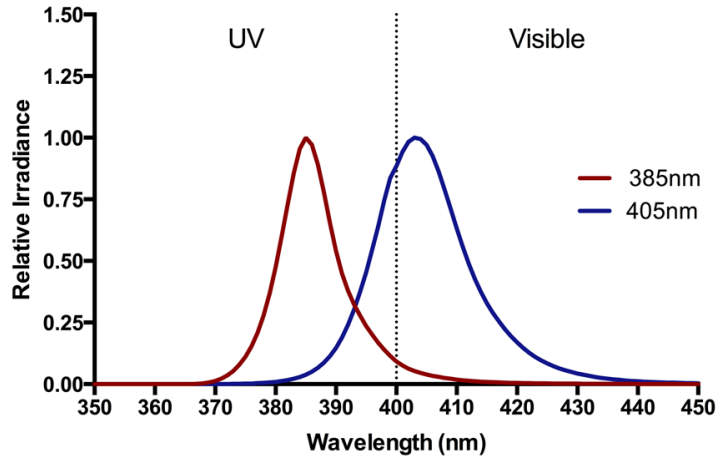

Figure 7. The spectral outputs of the experimental sources. The spectral output of the $385 \mathrm{~nm}$ and $405 \mathrm{~nm}$ Loctite LED sources used in all the studies. The full width at half maximum (FWHM) of the sources were $7 \mathrm{~nm}$ and $10 \mathrm{~nm}$ respectively. Spectra $(350-450 \mathrm{~nm})$ were measured with a Bentham spectroradiometer.

\section{Materials and Methods}

Radiation sources. The radiation sources used were Loctite LED flood array systems with peak outputs at 385 and $405 \mathrm{~nm}$ (Loctite, Henkel Ltd, UK). Each array has an irradiation surface of $97 \mathrm{~mm} \times 96 \mathrm{~mm}$ consisting of 144 LED. The spectral irradiances of both sources are shown in Fig. 7. Spectra were measured using a DM120BC double-monochromator spectroradiometer (Bentham Instruments, Reading, UK) using an integration sphere, calibrated by the Centre for Radiation, Chemical and Environmental Hazards (CRCE), Public Health England (PHE) against a UK national standard. Irradiance of the sources was routinely measured with a Loctite UVA/Vis radiometer (Loctite, Henkel Ltd, UK). Typical irradiances were $74 \mathrm{~mW} / \mathrm{cm}^{2}$ for the $385 \mathrm{~nm}$ source and $260 \mathrm{~mW} / \mathrm{cm}^{2}$ for the $405 \mathrm{~nm}$ sources, with irradiation times for the highest dose of $150 \mathrm{~J} / \mathrm{cm}^{2}$ of 34 minutes and 9.5 minutes respectively. Solar simulated radiation (SSR) was used as a positive control in some assays and the source used has been described previously ${ }^{59}$.

Cell culture. The immortalised human keratinocyte cell line HaCaT was purchased from ATCC (Manassas, Virginia, USA) and cultured in 48 well plates in Dulbecco's modified Eagle's medium (DMEM; Invitrogen, Paisley, UK), supplemented with $10 \%(\mathrm{v} / \mathrm{v}$ ) foetal calf serum (FCS), $100 \mathrm{U} / \mathrm{ml}$ penicillin and $100 \mu \mathrm{g} / \mathrm{ml}$ streptomycin (Invitrogen Paisley, UK). Cells were incubated in a humidified atmosphere $\left(5 \% \mathrm{CO}_{2}\right.$ at $\left.37^{\circ} \mathrm{C}\right)$.

Ethical approval \& volunteer recruitment. The in vivo study was approved by the National Research Ethics Service City and East (Ref: 13/LO/0380) and the Guy's and St Thomas' NHS Foundation Trust Research and Development department (Ref: RJ115/N205) and conducted in accordance with the Declaration of Helsinki Principles. All volunteers gave written informed consent. Volunteers of skin types I-III were recruited with details described in Table 3.

Biopsy procedure. Punch biopsies ( $4 \mathrm{~mm}$ diameter) were taken under local anaesthetic from the centre of each treated site at different time points (0-24 hrs) post exposure. An adjacent non-exposed site was also biopsied. Biopsies were divided into two halves. Biopsies for DNA damage analysis were immediately snap frozen in liquid nitrogen and stored at $-80^{\circ} \mathrm{C}$ until transport on dry ice to Grenoble, France where they were stored at $-80^{\circ} \mathrm{C}$ until analysis. Biopsies for gene expression were placed in RNA later and stored at $-80^{\circ} \mathrm{C}$ until extraction.

Irradiation procedure. In vitro. All assays were performed on HaCat cells grown as a 70-80\% confluent monolayer in multiwell plates. Cells were were washed three times in phosphate buffered saline (PBS) (Invitrogen, Paisley, UK). The cells were then irradiated with either $385 \mathrm{~nm}$ or $405 \mathrm{~nm}$ radiation $\left(0-150 \mathrm{~J} / \mathrm{cm}^{2}\right)$ as a single expsoure. Doses were selected based on those that are environmentally relevant and used for phototherapy, as well as refelecting the literature. Temperature was controlled with a cooling platform. After irradiation, PBS was removed and replaced with media or processed immediately depending on the experimental design.

In vivo. $1 \mathrm{~cm}^{2}$ irradiation sites on the upper sun-protected buttocks of healthy volunteers were exposed to a dose of $150 \mathrm{~J} / \mathrm{cm}^{2}$ of $385 \mathrm{~nm}$ or $405 \mathrm{~nm}$ light (as a single exposure) from a distance of $15 \mathrm{~cm}$ from the source. An adjacent site was left unexposed for the control biopsy. A fan was used to cool irradiation sites to ensure the skin did not overheat.

Cell Viability. Neutral red assay. Cell viability was measured 24 hrs post-irradiation using the Neutral Red uptake assay. Neutral Red solution ( $4 \mu \mathrm{g} / \mathrm{ml}$ in growth medium) (Sigma, Gillingham, UK) was added to the cells and incubated at $37^{\circ} \mathrm{C}, 5 \% \mathrm{CO}_{2}$ for 2 hrs. Cells were washed three times in PBS and the destain solution ( $50 \% \mathrm{v} / \mathrm{v}$ ethanol, $49 \% \mathrm{v} / \mathrm{v} \mathrm{ddH}_{2} \mathrm{O}, 1 \% \mathrm{v} / \mathrm{v}$ glacial acetic acid) was added. Optical density was measured at $540 \mathrm{~nm}$ using a Spectra Max 384 Plus spectrophotometer (Molecular Devices, Sunnyvale, California, USA).

Alamar blue assay. Alamar Blue solution $\left(1 / 10^{\text {th }}\right.$ of total growth medium volume) (ThermoFisher, Waltham, Massachusetts, USA) was added to the cells which were incubated at $37^{\circ} \mathrm{C}, 5 \% \mathrm{CO}_{2}$ for $4 \mathrm{hrs}$ and protected from light. The excitation/emission $=540-570 / 580-610 \mathrm{~nm}$ was used to measure fluorescence using a Spectra Max 384 Plus spectrophotometer. Each condition was tested in triplicate and the average calculated. 


\begin{tabular}{|l|l|l|l|l|}
\hline No. & Age & Sex & Skin Type & Endpoint \\
\hline 1 & 21 & M & II & Gene Expression \\
\hline 2 & 32 & F & II & DNA Damage + Gene Expression \\
\hline 3 & 26 & M & III & DNA Damage + Gene Expression \\
\hline 4 & 27 & M & II & DNA Damage + Gene Expression \\
\hline 5 & 21 & F & III & DNA Damage + Gene Expression \\
\hline 6 & 28 & F & I & DNA Damage \\
\hline 7 & 23 & M & II & DNA Damage \\
\hline 8 & 27 & M & II & DNA Damage \\
\hline 9 & 18 & M & II & DNA Damage \\
\hline
\end{tabular}

Table 3. Details of human volunteers and the endpoint for which samples were used.

Measurement of oxidizing species. Levels of ROS were assessed using the probe carboxy- $\mathrm{H}_{2} \mathrm{DCFDA}$. It is however accepted that other species may also oxidize this probe to its fluorescent product and this must be considered and hence the term oxidizing species is used ${ }^{60}$. Cells were treated and immediately incubated with $10 \mu \mathrm{M}$ carboxy $-\mathrm{H}_{2} \mathrm{DCFDA}$ (Invitrogen, Paisley, UK) in PBS for $30 \mathrm{mins}$ in the dark at $37^{\circ} \mathrm{C}, 5 \% \mathrm{CO}_{2}$. Cells were washed in PBS, trypsinised for $10 \mathrm{mins}$ at $37^{\circ} \mathrm{C}$, centrifuged at $1200 \mathrm{rpm}$ for $5 \mathrm{mins}$ at room temperature and then resuspended in PBS and counterstained with 4',6-diamidino-2-phenylindole (DAPI) for analysis by fluorescence activated cell sorting (FACS) using a Becton Dickinson FACSAria II (Becton Dickinson, Franklin Lakes, New Jersey, USA). Cells were gated to only analyse live cells (DAPI negative) and the average mean green intensity per condition was then plotted from at least 10,000 measured events. Analysis was carried out using FlowJo 8.7 software (Flowjo LLC, Ashland, Oregon, USA).

Immunocytochemistry - imunnofluorscence (IHC-IF) for CPD. Cells were treated and immediately washed, then fixed in $2 \%(\mathrm{v} / \mathrm{v})$ paraformaldehyde with $0.5 \%(\mathrm{v} / \mathrm{v})$ Triton X-100 in PBS for 30 mins at $4{ }^{\circ} \mathrm{C}$. DNA was then denatured by incubation in $2 \mathrm{M} \mathrm{HCl}$ for $10 \mathrm{mins}$ at $37^{\circ} \mathrm{C}$. Non-specific sites were blocked using blocking buffer of $20 \%(\mathrm{v} / \mathrm{v})$ goat serum and $0.1 \%(\mathrm{v} / \mathrm{v})$ triton $\mathrm{x}-100$ in PBS for $30 \mathrm{mins}$ at room temperature. Anti-CPD antibody (Clone TDM-2 which recognizes TT, TC, CT and CC CPD lesions) (Cosmobio, Tokyo, Japan) was added at 1:1000 in blocking buffer for $1 \mathrm{hr}$ at room temperature. Alexa Fluor ${ }^{\circledR} 488$ was diluted in blocking buffer (1:200 dilution) and incubated for $1 \mathrm{hr}$ at room temperature and finally DAPI was added for 10 mins. Washing was carried out with PBS $(3 \times 5$ mins $)$ between each step. Image capture of cells was carried out using a Ziess Axio-Observer Z1 Microscope (Carl Zeiss, Cambridge,U.K.) with AxioVision V.4.8 software (Carl Zeiss). Image analysis was carried out using Cell Profiler v.2.1.1 (Broad Institute, Cambridge, MA, U.S.A.), gating around the nucleus of each cell and the relative mean green intensity (CPD staining) of each nucleus was measured ( 150 nuclei measured per condition). The mean of the nine pictures was determined and used as the end point.

HPLC tandem mass spectrometry (HPLC-MS/MS). DNA damage in vivo was assessed at $0,2,4,6$ and $24 \mathrm{hrs}$ post-exposure by HPLC-MS/MS as previously described ${ }^{61}$. Results were expressed as the number of bipyrimidine photoproducts $/ 10^{6}$ normal bases. The analysis was for thymine dimers (TT) because they are the most frequent CPD. HPLC-MS/MS was only used for in vivo samples, as it is the most sensitive method available and gave the greatest chance of detecting lesions in the best available model.

RNA extraction and qRT-PCR. RNA was extracted using the mirVana miRNA Isolation kit (Life Technologies, Paisley, UK) RNA was reversely transcribed to cDNA using the High Capacity cDNA Reverse Transcription Kit (Applied Biosystems, Paisley, UK) as previously described ${ }^{59}$. qPCR was performed using TaqMan Gene Expression Assays (Applied Biosystems, Massachusetts, USA) according to the manufacturer's protocols. GAPDH was used as the housekeeping gene. Gene fold change was measured using the $\Delta \Delta \mathrm{CT} \operatorname{method}^{62}$. Gene selection was based on previous in vivo human studies ${ }^{52}$ and the literature.

For in vivo data, many genes showed a large fold change, but when tested statistically this was not significantly different from the non-irradiated controls The normality of the pooled data was tested and it was found that data were not normally distributed when assessed by the D’Agostino and Pearson test $(\mathrm{p}<0.0001)$ so the data were logged to normalise the data before further analysis ${ }^{63}$. Genes with similar end points were pooled (for inflammation, photoageing and oxidative stress), and two-way ANOVA was performed. This approach led to more robust data.

Statistical analysis. All data are expressed as the mean \pm standard deviation (SD) where $\mathrm{n} \geq 3$. Statistical analyses were carried out using Graphpad Prism 6.0 (Graphpad Software, San Diego, CA) and were evaluated using the student's t-test, ANOVA, linear and non-linear regression. Significance limits were set as: $*=p \leq 0.05$, $* *=\mathrm{p} \leq 0.001, * * *=\mathrm{p} \leq 0.0001$.

Data availability statement. All data generated or analysed during this study are included in this published article (and its Supplementary Information files). 


\section{References}

1. Gambichler, T., Terras, S. \& Kreuter, A. Treatment regimens, protocols, dosage, and indications for UVA1 phototherapy: facts and controversies. Clinics in dermatology 31, 438-454, https://doi.org/10.1016/j.clindermatol.2013.01.011 (2013).

2. Tewari, A. et al. Successful treatment of microstomia with UVA1 phototherapy in systemic sclerosis. Photodermatology, photoimmunology \& photomedicine 27, 113-114, https://doi.org/10.1111/j.1600-0781.2011.00570.x (2011).

3. Liebel, F., Kaur, S., Ruvolo, E., Kollias, N. \& Southall, M. D. Irradiation of skin with visible light induces reactive oxygen species and matrix-degrading enzymes. The Journal of investigative dermatology 132, 1901-1907, https://doi.org/10.1038/jid.2011.476 (2012).

4. Zastrow, L. \& Lademann, J. Light - Instead of UV Protection: New Requirements for Skin Cancer Prevention. Anticancer research 36, 1389-1393 (2016).

5. McAdam, E., Brem, R. \& Karran, P. Oxidative stress-induced protein damage inhibits DNA repair and determines mutation risk and therapeutic efficacy. Molecular cancer research: MCR, https://doi.org/10.1158/1541-7786.mcr-16-0053 (2016).

6. Courdavault, S. et al. Larger yield of cyclobutane dimers than 8-oxo-7,8-dihydroguanine in the DNA of UVA-irradiated human skin cells. Mutation research 556, 135-142, https://doi.org/10.1016/j.mrfmmm.2004.07.011 (2004).

7. Kvam, E. \& Tyrrell, R. M. Induction of oxidative DNA base damage in human skin cells by UV and near visible radiation. Carcinogenesis 18, 2379-2384, https://doi.org/10.1093/carcin/18.12.2379 (1997).

8. Rosenstein, B. S. \& Mitchell, D. L. Action spectra for the induction of pyrimidine(6-4)pyrimidone photoproducts and cyclobutane pyrimidine dimers in normal human skin fibroblasts. Photochemistry and photobiology 45, 775-780 (1987).

9. Kielbassa, C., Roza, L. \& Epe, B. Wavelength dependence of oxidative DNA damage induced by UV and visible light. Carcinogenesis 18, 811-816 (1997).

10. Brash, D. E. UV Signature Mutations. Photochemistry and photobiology. https://doi.org/10.1111/php.12377 (2014).

11. Premi, S. et al. Chemiexcitation of melanin derivatives induces DNA photoproducts long after UV exposure. Science 347, 842-847, https://doi.org/10.1126/science.1256022 (2015).

12. Delinasios, G. J., Karbaschi, M., Cooke, M. S. \& Young, A. R. Vitamin E inhibits the UVAI induction of "light" and "dark" cyclobutane pyrimidine dimers, and oxidatively generated DNA damage, in keratinocytes. Scientific reports 8, 423, https://doi. org/10.1038/s41598-017-18924-4 (2018).

13. Chiarelli-Neto, O. et al. Melanin photosensitization and the effect of visible light on epithelial cells. PloS one 9, e113266, https://doi. org/10.1371/journal.pone.0113266 (2014).

14. Schmitz, S., Thomas, P. D., Allen, T. M., Poznansky, M. J. \& Jimbow, K. Dual role of melanins and melanin precursors as photoprotective and phototoxic agents: inhibition of ultraviolet radiation-induced lipid peroxidation. Photochemistry and photobiology 61, 650-655 (1995).

15. Wood, S. R. et al. UV causation of melanoma in Xiphophorus is dominated by melanin photosensitized oxidant production. Proceedings of the National Academy of Sciences of the United States of America 103, 4111-4115, https://doi.org/10.1073/ pnas.0511248103 (2006).

16. Noonan, F. P. et al. Melanoma induction by ultraviolet A but not ultraviolet B radiation requires melanin pigment. Nature Communications 3, 884, https://doi.org/10.1038/ncomms1893 (2012).

17. Hill, H. Z. \& Hill, G. J. Eumelanin Causes DNA Strand Breaks and Kills Cells. Pigment Cell Research 1, 163-170, https://doi. org/10.1111/j.1600-0749.1987.tb00408.x (1987).

18. Quan, T. et al. Matrix-degrading metalloproteinases in photoaging. The journal of investigative dermatology. Symposium proceedings/the Society for Investigative Dermatology, Inc. [and] European Society for Dermatological Research 14, 20-24, https://doi. org/10.1038/jidsymp.2009.8 (2009).

19. C S Fau, et al. Infrared plus visible light and heat from natural sunlight participate in the expression of MMPs and type I procollagen as well as infiltration of inflammatory cell in human skin in vivo. (2008).

20. Kleinpenning, M. M. et al. Clinical and histological effects of blue light on normal skin. Photodermatology, photoimmunology \& photomedicine 26, 16-21, https://doi.org/10.1111/j.1600-0781.2009.00474.x (2010).

21. Slominski, A. T., Zmijewski, M. A., Plonka, P. M., Szaflarski, J. P. \& Paus, R. How UV Light Touches the Brain and Endocrine System Through Skin, and Why. Endocrinology 159, 1992-2007, https://doi.org/10.1210/en.2017-03230 (2018).

22. Diffey, B. \& Osterwalder, U. Labelled sunscreen SPFs may overestimate protection in natural sunlight. Photochemical \& Photobiological Sciences, https://doi.org/10.1039/C7PP00260B (2017).

23. Oplander, C. et al. Whole body UVA irradiation lowers systemic blood pressure by release of nitric oxide from intracutaneous photolabile nitric oxide derivates. Circulation research 105, 1031-1040, https://doi.org/10.1161/circresaha.109.207019 (2009).

24. Holliman, G., Lowe, D., Cohen, H., Felton, S. \& Raj, K. Ultraviolet Radiation-Induced Production ofNitric Oxide:A multi-cell and multi-donor analysis. Scientific reports 7, 11105, https://doi.org/10.1038/s41598-017-11567-5 (2017).

25. Oplander, C. et al. Mechanism and biological relevance of blue-light (420-453 nm)-induced nonenzymatic nitric oxide generation from photolabile nitric oxide derivates in human skin in vitro and in vivo. Free radical biology \& medicine 65, 1363-1377, https://doi. org/10.1016/j.freeradbiomed.2013.09.022 (2013).

26. Randhawa, M. et al. Visible Light Induces Melanogenesis in Human Skin through a Photoadaptive Response. PloS one 10, e0130949, https://doi.org/10.1371/journal.pone.0130949 (2015).

27. Regazzetti, C. et al. Melanocytes sense blue light and regulate pigmentation through the Opsin3. The Journal of investigative dermatology. https://doi.org/10.1016/j.jid.2017.07.833 (2017).

28. Wolfle, U. et al. Reactive molecule species and antioxidative mechanisms in normal skin and skin aging. Skin pharmacology and physiology 27, 316-332, https://doi.org/10.1159/000360092 (2014).

29. Nakashima, Y., Ohta, S. \& Wolf, A. M. Blue light-induced oxidative stress in live skin. Free radical biology \& medicine, https://doi. org/10.1016/j.freeradbiomed.2017.03.010 (2017).

30. Biesalski, H. K. \& Obermueller-Jevic, U. C. UV light, beta-carotene and human skin-beneficial and potentially harmful effects. Archives of biochemistry and biophysics 389, 1-6, https://doi.org/10.1006/abbi.2001.2313 (2001).

31. Blazquez-Castro, A. et al. Protoporphyrin IX-dependent photodynamic production of endogenous ROS stimulates cell proliferation. European journal of cell biology 91, 216-223, https://doi.org/10.1016/j.ejcb.2011.12.001 (2012).

32. Sarkany, R. P. Erythropoietic protoporphyria (EPP) at 40. Where are we now? Photodermatology, photoimmunology \& photomedicine 18, 147-152 (2002).

33. Dalle Carbonare, M. \& Pathak, M. A. Skin photosensitizing agents and the role of reactive oxygen species in photoaging. Journal of photochemistry and photobiology. B, Biology 14, 105-124 (1992).

34. Juzeniene, A., Thu Tam, T. T., Iani, V. \& Moan, J. 5-Methyltetrahydrofolate can be photodegraded by endogenous photosensitizers. Free radical biology \& medicine 47, 1199-1204, https://doi.org/10.1016/j.freeradbiomed.2009.07.030 (2009).

35. Ravanat, J. L., Di Mascio, P., Martinez, G. R. \& Medeiros, M. H. Singlet oxygen induces oxidation of cellular DNA. The Journal of biological chemistry 276, 40601-40604 (2001).

36. Mizutani, T., Sumida, H., Sagawa, Y., Okano, Y. \& Masaki, H. Carbonylated proteins exposed to UVA and to blue light generate reactive oxygen species through a type I photosensitizing reaction. Journal of dermatological science, https://doi.org/10.1016/j. jdermsci.2016.09.016 (2016).

37. Young, A. R. et al. The similarity of action spectra for thymine dimers in human epidermis and erythema suggests that DNA is the chromophore for erythema. The Journal of investigative dermatology 111, 982-988, https://doi.org/10.1046/j.1523-1747.1998.00436.x (1998). 
38. Petersen, B. et al. Sun and ski holidays improve vitamin D status, but are associated with high levels of DNA damage. The Journal of investigative dermatology 134, 2806-2813, https://doi.org/10.1038/jid.2014.223 (2014).

39. Douki, T., Reynaud-Angelin, A., Cadet, J. \& Sage, E. Bipyrimidine photoproducts rather than oxidative lesions are the main type of DNA damage involved in the genotoxic effect of solar UVA radiation. Biochemistry 42, 9221-9226, https://doi.org/10.1021/ bi034593c (2003).

40. Freeman, S. E. et al. Wavelength dependence of pyrimidine dimer formation in DNA of human skin irradiated in situ with ultraviolet light. Proceedings of the National Academy of Sciences of the United States of America 86, 5605-5609 (1989).

41. Young, A. R. et al. Human melanocytes and keratinocytes exposed to UVB or UVA in vivo show comparable levels of thymine dimers. The Journal of investigative dermatology 111, 936-940, https://doi.org/10.1046/j.1523-1747.1998.00435.x (1998).

42. Mouret, S. et al. UVA-induced cyclobutane pyrimidine dimers in DNA: a direct photochemical mechanism? Organic \& biomolecular chemistry 8, 1706-1711, https://doi.org/10.1039/b924712b (2010).

43. Tewari, A., Sarkany, R. P. \& Young, A. R. UVA1 induces cyclobutane pyrimidine dimers but not 6-4 photoproducts in human skin in vivo. The Journal of investigative dermatology 132,394-400, https://doi.org/10.1038/jid.2011.283 (2012).

44. Fajuyigbe, D. et al. Melanin distribution in human epidermis affords localized protection against DNA photodamage and concurs with skin cancer incidence difference in extreme phototypes. FASEB journal: official publication of the Federation of American Societies for Experimental Biology, fj201701472R, https://doi.org/10.1096/f.201701472R (2018).

45. Beltrán-García, M. J. et al. Singlet Molecular Oxygen Generation by Light-Activated DHN-Melanin of the Fungal Pathogen Mycosphaerella fijiensis in Black Sigatoka Disease of Bananas. PloS one 9, e91616, https://doi.org/10.1371/journal.pone.0091616 (2014).

46. Ito, S., Wakamatsu, K. \& Sarna, T. Photodegradation of Eumelanin and Pheomelanin and Its Pathophysiological Implications. Photochemistry and photobiology 94, 409-420, https://doi.org/10.1111/php.12837 (2018).

47. Szewczyk, G. et al. Aerobic photoreactivity of synthetic eumelanins and pheomelanins: generation of singlet oxygen and superoxide anion. Pigment cell \& melanoma research 29, 669-678, https://doi.org/10.1111/pcmr.12514 (2016).

48. Wondrak, G. T., Jacobson, M. K. \& Jacobson, E. L. Endogenous UVA-photosensitizers: mediators of skin photodamage and novel targets for skin photoprotection. Photochemical \& photobiological sciences: Official journal of the European Photochemistry Association and the European Society for Photobiology 5, 215-237, https://doi.org/10.1039/b504573h (2006).

49. Young, A. R. et al. The in situ repair kinetics of epidermal thymine dimers and 6-4 photoproducts in human skin types I and II. The Journal of investigative dermatology 106, 1307-1313 (1996).

50. Courdavault, S. et al. Repair of the three main types of bipyrimidine DNA photoproducts in human keratinocytes exposed to UVB and UVA radiations. DNA repair 4, 836-844, https://doi.org/10.1016/j.dnarep.2005.05.001 (2005).

51. Young, A. R., Orchard, G. E., Harrison, G. I. \& Klock, J. L. The detrimental effects of daily sub-erythemal exposure on human skin in vivo can be prevented by a daily-care broad-spectrum sunscreen. The Journal of investigative dermatology 127, 975-978, https:// doi.org/10.1038/sj.jid.5700606 (2007).

52. Tewari, A. The cellular and molecular effects of UVA1 on human skin in vivo: impact on human health Ph.D thesis, King's College London, (2015).

53. Tewari, A., Lahmann, C., Sarkany, R., Bergemann, J. \& Young, A. R. Human erythema and matrix metalloproteinase-1 mRNA induction, in vivo, share an action spectrum which suggests common chromophores. Photochemical \& photobiological sciences: Official journal of the European Photochemistry Association and the European Society for Photobiology 11, 216-223, https://doi. org/10.1039/c1pp05243h (2012).

54. Dong, K. K. et al. UV-induced DNA damage initiates release of MMP-1 in human skin. Experimental dermatology 17, 1037-1044, https://doi.org/10.1111/j.1600-0625.2008.00747.x (2008).

55. Kim, M. S., Kim, Y. K., Cho, K. H. \& Chung, J. H. Regulation of type I procollagen and MMP-1 expression after single or repeated exposure to infrared radiation in human skin. Mech Ageing Dev 127, 875-882, https://doi.org/10.1016/j.mad.2006.09.007 (2006).

56. Lehman, T. A. et al. p53 mutations in human immortalized epithelial cell lines. Carcinogenesis 14, 833-839 (1993).

57. Diffey, B. Solar spectral irradiance and summary outputs using excel. Photochemistry and photobiology 91, 553-557, https://doi. org/10.1111/php.12422 (2015).

58. Kerr, A. C. et al. Ultraviolet A1 phototherapy: a British Photodermatology Group workshop report. Clinical and experimental dermatology 37, 219-226, https://doi.org/10.1111/j.1365-2230.2011.04256.x (2012).

59. Lawrence, K. P., Gacesa, R., Long, P. F. \& Young, A. R. Molecular photoprotection of human keratinocytes in vitro by the naturally occurring mycosporine-like amino acid (MAA) palythine. The British journal of dermatology, https://doi.org/10.1111/bjd.16125 (2017).

60. Kalyanaraman, B. et al. Measuring reactive oxygen and nitrogen species with fluorescent probes: challenges and limitations. Free radical biology \& medicine 52, 1-6, https://doi.org/10.1016/j.freeradbiomed.2011.09.030 (2012).

61. Douki, T. The variety of UV-induced pyrimidine dimeric photoproducts in DNA as shown by chromatographic quantification methods. Photochemical \& photobiological sciences: Official journal of the European Photochemistry Association and the European Society for Photobiology 12, 1286-1302, https://doi.org/10.1039/c3pp25451h (2013).

62. Livak, K. J. \& Schmittgen, T. D. Analysis of relative gene expression data using real-time quantitative PCR and the 2(-Delta Delta C(T)) Method. Methods (San Diego, Calif.) 25, 402-408, https://doi.org/10.1006/meth.2001.1262 (2001).

63. D’Agnostino, R. B. \& Pearson, E. S. Testing for departures from normality. I. Fuller empirical results for the distribution of b2 and $\sqrt{ }$ b1. Biometrika 60, 613-622 (1973).

\section{Acknowledgements}

The authors would like to thank Dr. Mieran Sethi and Dr. Wisam Alwan for clinical support and all the volunteers for taking part. This study was supported by the National Institute for Health Research (NIHR) Clinical Research Facility at Guy's \& St. Thomas' NHS Foundation Trust and NIHR Biomedical Research Centre based at Guy's and St. Thomas' NHS Foundation Trust and King's College London. The views expressed are those of the author(s) and not necessarily those of the NHS, the NIHR or the Department of Health.

\section{Author Contributions}

K.P.L., A.R.Y., B.H. \& S.A. conceived and designed the study. K.P.L. and T.D. performed experiments. K.P.L. and A.R.Y. wrote the manuscript. R.P.E.S. was liable for clinical responsibility of the project. All authors contributed to and reviewed the manuscript.

\section{Additional Information}

Supplementary information accompanies this paper at https://doi.org/10.1038/s41598-018-30738-6.

Competing Interests: B.H. and S.A. are employees of BASF GmbH who funded this research. BASF GmbH funded K.P.L. Studentship. A.R.Y., T.D. and R.P.E.S. declare no potential conflicts of interest. 
Publisher's note: Springer Nature remains neutral with regard to jurisdictional claims in published maps and institutional affiliations.

(c) (i) Open Access This article is licensed under a Creative Commons Attribution 4.0 International License, which permits use, sharing, adaptation, distribution and reproduction in any medium or format, as long as you give appropriate credit to the original author(s) and the source, provide a link to the Creative Commons license, and indicate if changes were made. The images or other third party material in this article are included in the article's Creative Commons license, unless indicated otherwise in a credit line to the material. If material is not included in the article's Creative Commons license and your intended use is not permitted by statutory regulation or exceeds the permitted use, you will need to obtain permission directly from the copyright holder. To view a copy of this license, visit http://creativecommons.org/licenses/by/4.0/.

(c) The Author(s) 2018 